\title{
Silver Nanotoxicity on Kidneys and Ovaries of Female Albino Rats
}

\author{
Mohamed Mahmoud Nabeh ${ }^{1}$, Yasmeen M. Taalab ${ }^{1 *}$, Doaa Abd El-Wahab El Morsi ${ }^{1}$, Samar \\ Adel Asker ${ }^{2}$, Ahmed Mohamed Elbedwehy $^{3}$, Mona Ahmed El-Harouny ${ }^{1}$
}

\begin{abstract}
KEYWORDS

Silver nanoparticles; Renal toxicity;

Ovarian toxicity;

Reactive oxygen species;

MDA;

SOD;

GPx.

Silver nanoparticles (AgNPs) are widely involved in the medical products owing to their antibacterial activity. However, their extensive use causes human hazards via dermal, inhalational and parenteral routes. The aim of the current study was to investigate the toxic effect of different doses of AgNPs on the ovaries and the kidneys of the adult female Albino Rats. Forty female rats were randomly allocated to three treated groups and a control to assess the toxic effect of AgNPs injected intraperitoneally at $1,2,4 \mathrm{mg} / \mathrm{kg}$ respectively over a period of 28 days. Renal and ovarian tissues together with blood samples were collected and examined for biochemicals, hormonal and histopathological changes. The results revealed a decrease in Luteinizing hormone (LH) and Follicle-Stimulating hormone (FSH) in addition to increased levels of Blood Urea Nitrogen (BUN) and serum creatinine among the studied groups in comparison to the control. Furthermore, there were considerable generations of reactive oxygen species (ROS) expressed by elevated plasma malonaldehyde (MDA) level and decreased antioxidant glutathione peroxidase (GPx) and antioxidants-superoxide dismutase (SOD) levels together with demonstration of histopathological alterations in the renal and ovarian tissues in the three studied groups compared to the control group. Conclusively, renal and ovarian tissues displayed both functional and histopathological structural alteration following exposure to AgNPs in a characteristic dose-dependent manner. This can be partly explained by generation of ROS indicated by elevation of MDA level and reduction of GPX and SOD levels.
\end{abstract}

\section{Introduction}

Nanotechnology is the field that deals with nanoparticles (NPs) having at least one spatial dimension and their size ranges one to 100 nanometers $(\mathrm{nm})$ with a surrounding

\footnotetext{
${ }^{\left({ }^{(I)} \text { Forensic Medicine and Clinical Toxicology }\right.}$ Department, Faculty of Medicine, Mansoura University, Egypt.

${ }^{(2)}$ Histology and Cell Biology Department, Faculty of Medicine, Mansoura University, Egypt,

${ }^{(3)}$ Nanotechnology Center, Mansoura University, Egypt.

*Corresponding author: Dr.Yasmeen Taalab, MD, PhD dryasmeen.taalab@mans.edu.eg
}

interfacial layer. The interfacial layer consists of ions, organic and inorganic molecules. The organic molecules which coats inorganic nanoparticles are known as stabilizers or capping agents. The interfacial layer is an integral part of nanoscale matter, essentially affecting all of its properties (Batista et al., 2015).

Among several nanoparticles, metal nanoparticles are the most talented owing to their anti-bacterial activities which occurs due to high surface to volume ratio. Change in its surface or size can change the chemical and physical properties of the nanoparticles and 
therefore, they have been used in a wide variety of applications. The mechanisms of bacterial killing include the generation of reactive oxygen species, biomolecule damages, cation release and depletion of adenosine triphosphate (ATP) (Slavin et al., 2017).

Silver nanoparticles (AgNPs) are a remarkable nanoproducts that attracted considerable attention not only as antimicrobial agents but rather for their incorporation in a number of consumer products including cosmetics, textiles, food boxes and sprays, machines such as refrigerators and washing machine sand, medical uses such as medical devices, wound dressings, drug-delivery systems and imaging methods (Schäfer et al., 2013).

However, the extensive use of AgNPs may lead to human hazards via dermal, inhalation and parenteral routes which indeed, raising alarms about their potential environmental influence and toxicity. Direct ingestion of AgNPs via water, food, cosmetics, drugs, and drug delivery devices might result in releasing of silver ions into the blood which ultimately can accumulate in body organs and induce toxic effects, especially in the liver and kidney a (Park and Bae, 2010). It has been reported that AgNPs are more toxic than other metal nanoparticles, including aluminum, iron, nickel, and manganese but the mechanism of their toxicity is not clear (Sarhan and Hussein, 2014).

There were histopathological alterations in ovarian tissue following exposure to silver nanoparticles in rats with significant loss of germ cells compared to control group. In addition, there were changes in ovarian histopathology including inflammation, fibrosis, apoptosis and follicle degeneration in a dose and duration dependent manner (Han et al., 2016).
As regard the kidney, Tiwari et al. (2017) evaluated that after continued exposure to silver NPs, there was ultra-structural damage to renal tissue with subsequent inflammation and expression of cell survival factors. Such alterations, may lead to blocking of the valuable apoptotic pathway and promotion of necrotic cellular death in kidneys. Moreover, Wen et al. (2017) revealed that liver could be the most affected organs by an acute intravenous dosage of silver NPs, and markedly raised chromosomal breakdown and polyploidy cell proportions also implied the potential genotoxicity of silver NPs.

The current work aimed to study the toxicity of different doses of silver NPs as regards the biochemical, hormonal and histopathological changes in the ovaries and kidneys of adult female Albino rats.

\section{Material and Methods:}

\section{Material:}

1. Chemicals: Silver Nitrate $\left(\mathrm{AgNO}_{3}\right.$, $99.5 \%$ Sigma, USA) and other chemicals are purshased from SigmaAldrich, Germany.

2. Reagents for oxidative stress kits: malondialdehyde; superoxide dismutase and glutathione peroxidase were purchased from Bio - diagnostics, Egypt.

\section{Methods:}

1. Preparation of AgNPs: Silver nanoparticles were prepared by modified chemical reduction method (Abdel-Halim et al., 2011; Van Dong et al., 2012).

2. Characterization of AgNPs: include Ultraviolet visible absorption spectroscopy and transmission Electron 
Microscope (Model No JEM-2010, JEOL Company).

3. Particle size and distribution: The particle size, and size distribution were measured by zeta sizer (Malvern zeta sizer Nano ZS) based on the dynamic light scattering technique. The average of the particle size in the current study was $6 \mathrm{~nm}$ in diameter.

4. X-ray diffraction: Dried powder samples of silver nanoparticles were exposed to X-ray diffraction - D8 Advance X-Ray diffract meter; Bruker AXS using $\mathrm{Cu} \mathrm{K \alpha}$ radiation. X-ray diffraction pattern for silver nanoparticles was obtained. Silver NPs crystal size was determined by the following equation (Patterson, 1939).

\section{Animals and Experimental Protocol}

The present experimental study was performed on a total of 40 adult female Albino rats aged eight weeks and weighing between 200-250 grams. They were purchased from Mansoura Experimental Research Center (MERC) of the Faculty of Medicine, Mansoura University and utilized according to the guidelines of laboratory animal's care.

Rats were kept under controlled housing conditions. They divided into ten in each cage with temperature $22{ }^{0} \mathrm{C} \pm 1{ }^{\circ} \mathrm{C}$, humidity $60 \%$ \pm 10 in an adequately ventilated room under a regular $12 \mathrm{~h}$ light/12h dark cycle with free access to food and water ad libitum for 14 days before and during duration of the experiment. The Institutional Research Board of Faculty of Medicine at Mansoura University approved the experimental protocol (Code Number: MS/17.05.05).

The rats were randomly allocated into 4 groups (10 rats each): The control group and three treated groups (I, II, and III). The controls received $0.5 \mathrm{ml}$ deionized water daily by intraperitoneal (I.P) route for 28 days. The three treated groups received AgNPs of average size $7 \pm 3 \mathrm{~nm}$ daily by I.P route for 28 days as follows; Group I received $1 \mathrm{mg} / \mathrm{kg}$ bw (1/268 of LD50), Group II received $2 \mathrm{mg} / \mathrm{kg}$ bw (2/268 of LD50) and Group III received 4 $\mathrm{mg} / \mathrm{kg}$ bw (4/268 of LD50) (El Mahdy et al., 2015).

\section{Samples' Acquisition:} Blood:

At the end of 28 days-experiment and 24 hours after last dose injection (De Jong et al., 2013), two $\mathrm{ml}$ of blood was collected from each animal by orbital puncture using sterile disposable syringes in dry tube then centrifuged at 4000 r.p.m for 10 minutes then serum was collected and investigated for: Follicle Stimulating (FSH) and Luteinizing (LH) hormones as markers for female reproductive functions and, Serum creatinine $(\mathrm{Cr})$ and blood urea nitrogen (BUN) as the routine markers used in Kidney function tests.

\section{Organs/tissues:}

After collection of blood samples, rats were anaesthetized using chloroform (De Jong et al., 2013) and sacrificed by cervical dislocation. Prior to dissection, kidneys and ovaries were perfused through the heart with isotonic saline $(0.9 \% \mathrm{NaCl})$ containing heparin to wash any red blood cells from tissue samples. From each rat, both kidneys and ovaries were taken for:

- Oxidative stress biochemical study; Lipid peroxidation assay detecting malondialdehyde (MDA), and antioxidant enzymes activity assays detecting superoxide dismutase (SOD) and glutathione peroxidase (GPx) levels.

- Histopathological study; tissues were fixed in $10 \%$ buffered neutral formalin, dehydrated in ascending grades of alcohol then cleared with xylene and embedded in paraffin, sectioned at $5 \mu \mathrm{m}$ thickness, 
stained by Hematoxylin and Eosin stain and examined microscopically (Bancroft and Gamble, 2008).

\section{Statistical analysis:}

The collected data were coded, processed and analyzed using Statistical Package of Social Science (SPSS) program for windows (version 16). Quantitative continuous data were presented in mean \pm standard deviation (SD). One way analysis of variance (ANOVA) test was used for testing significance of parametric quantitative data. If the $\mathrm{p}$-value $<$ 0.05 , we reject null hypothesis $(\mathrm{H} 0)$ and conclude that there is a significant difference between at least one pair of means. Bonferroni post hoc test was used to perform pairwise comparisons between group means and to control overall error rate. Pearson correlation (r) was used to measure the strength of correlation between two continuous variables which may be either positive $(+)$ or negative (-) correlation.

\section{Results:}

\section{A.Hormonal assay results:}

The effect of silver nanoparticles on the level of luteinizing and follicle stimulating hormones $(\mathrm{mIU} / \mathrm{ml})$ in the studied groups (as mean \pm SD) are represented in figure (1). There is highly significant decrease in $\mathrm{LH}$ level in the three test groups in comparison to the control group $(p<0.001)$. While there are no significant differences among the three studied groups $(p>0.05)$. While the lowest FSH level is recorded in group III followed by group II then group I with highly significant differences between all the studied groups and the control group $(p<0.001)$. However, no statistically significant differences have been demonstrated when comparing the three studied groups $(\mathrm{p}>0.05)$ (Figure 1$)$.

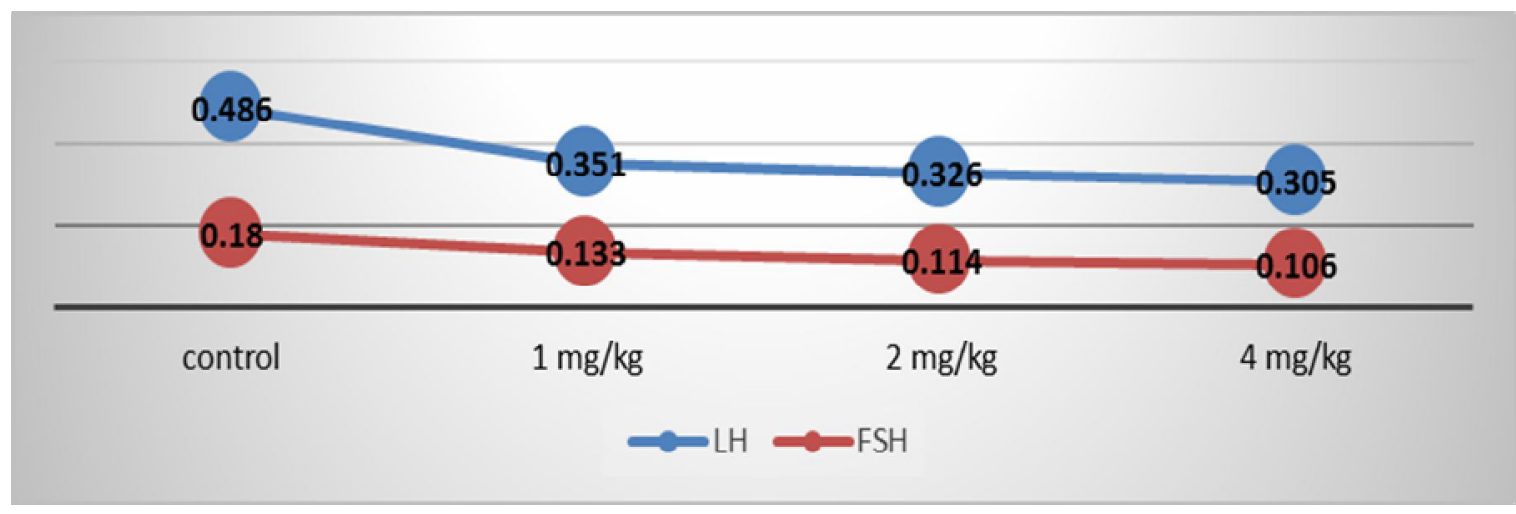

Fig. (1): Effect of silver nanoparticles on luteinizing and follicle stimulating hormones $(\mathrm{mIU} / \mathrm{ml})$ level in the studied groups. mIU: milli-international unit.

\section{B. Biochemical assay results:}

Figure (2) revealed the effect of silver nanoparticles on the level of serum creatinine $(\mathrm{Cr})$ and blood urea nitrogen $(\mathrm{BUN})(\mathrm{mg} / \mathrm{dl})$ in the studied groups (as mean $\pm \mathrm{SD}$ ) The highest level of serum $\mathrm{Cr}$ is found in group III with high statistically significant difference in comparison to the control group, group I and II $(\mathrm{p}<$ 0.001). Group II illustrates highly statistically significant difference in comparison with control group $(p<0.001)$ and no significant difference with group I. Serum $\mathrm{Cr}$ level in group I illustrates a significant difference $(\mathrm{p}<0.054)$ in comparison to control group (Figure 2). 
Regarding BUN; there is highly significant increase in BUN level in group III in comparison to the control, group I and II $(p<0.001)$. There are no significant differences between group I and group II in relation to the control group and between each other (Figure 2).

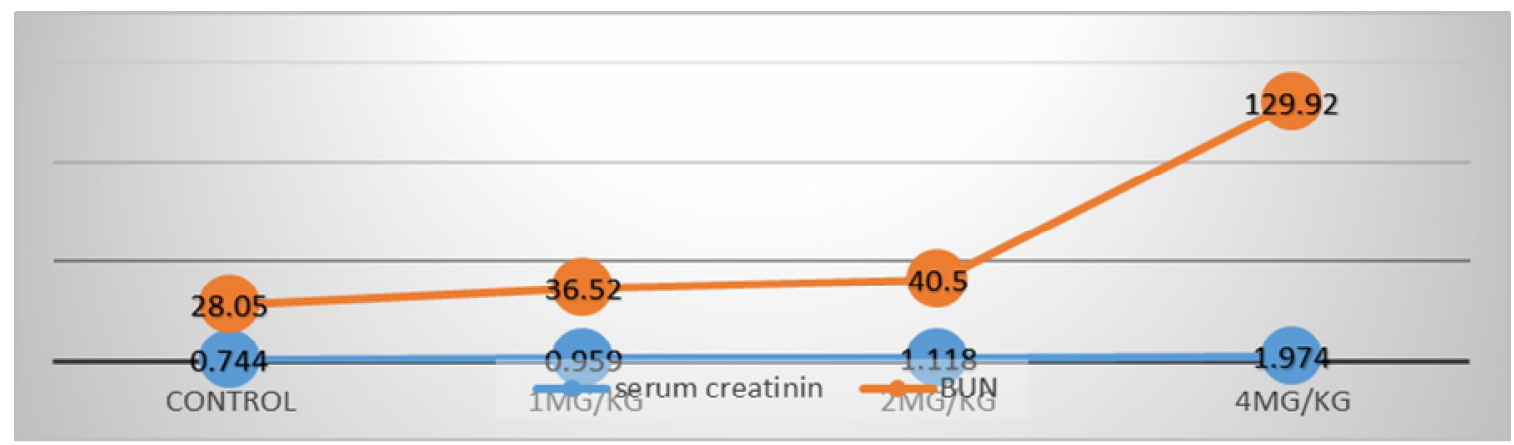

Fig. (2): Effect of silver nanoparticles on serum creatinine $(\mathrm{Cr})$ and blood urea nitrogen $(\mathrm{BUN})(\mathrm{mg} / \mathrm{dl})$ level in the studied groups.

\section{C.Oxidative stress biochemical results:}

The Effect of the three studied doses of AgNPs on renal and ovarian malondialdehyde (MDA) is illustrated in (Figure 3) (as mean \pm SD). The highest MDA level in kidneys is observed in group III followed by group II then group I. There are highly significant differences between the three test groups and the control group and among the three tested groups $(p<0.001)$. While the highest MDA level in ovaries is noticed in group III followed by group II then group I. There are highly significant differences between the three test groups and the control group and among the three test groups $(p<0.001)$.

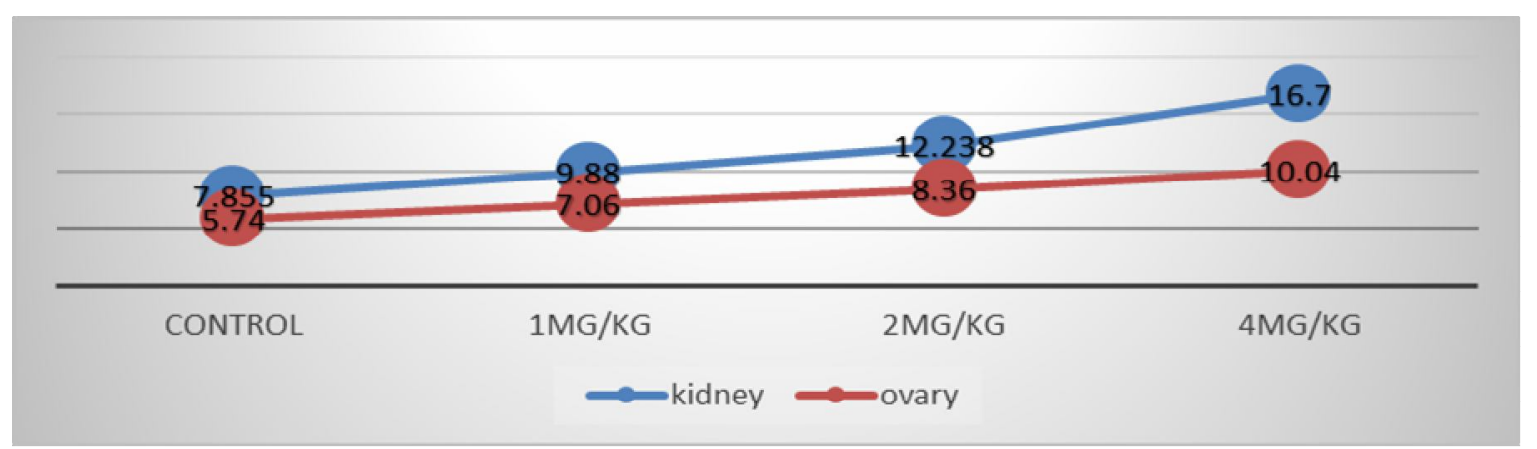

Fig. (3): Effect of silver nanoparticles on renal and ovarian malondialdehyde (nmo/gt) level in the studied group.

Furthermore, the Effect of the three studied doses of AgNPs on the renal and ovarian superoxide dismutase (SOD) as a marker for antioxidant activity is illustrated in figure (4) (as mean \pm SD). The lowest SOD level in kidneys is found in group III followed by group II then group I. There are highly significant differences between the three test groups and the control group and among the three test groups. While the lowest SOD level 
in ovaries presents in group III followed by group II then group I. There are highly significant differences between the three test groups and the control group and among the three test groups $(\mathrm{p}<0.001)$.

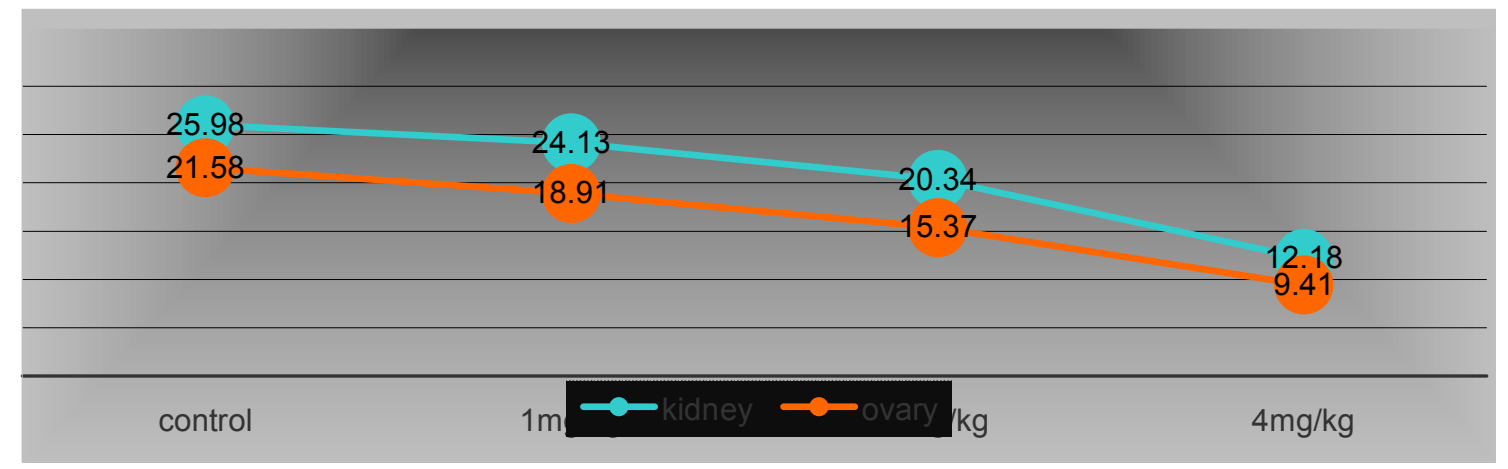

Fig. (4): Effects of silver nanoparticles on renal and ovarian superoxide dismutase (U/gt) level in the studied groups.

Moreover, the effect of the three studied doses of silver nanoparticles on the renal and ovarian glutathione peroxidase (GPx) level as a marker for antioxidant activity is demonstrated in figure (5) (as mean \pm SD). There is highly significant decrease in GPx level in kidneys in the three test groups in comparison to the control group. Additionally, there are highly significant differences between the three test groups and control group and among the three test groups themselves $(p<0.001)$. While the lowest GPx level in ovaries is showed in group III followed by group II then group I. Additionally, there are highly significant differences between the three test groups and the control group $(\mathrm{p}<0.001)$.

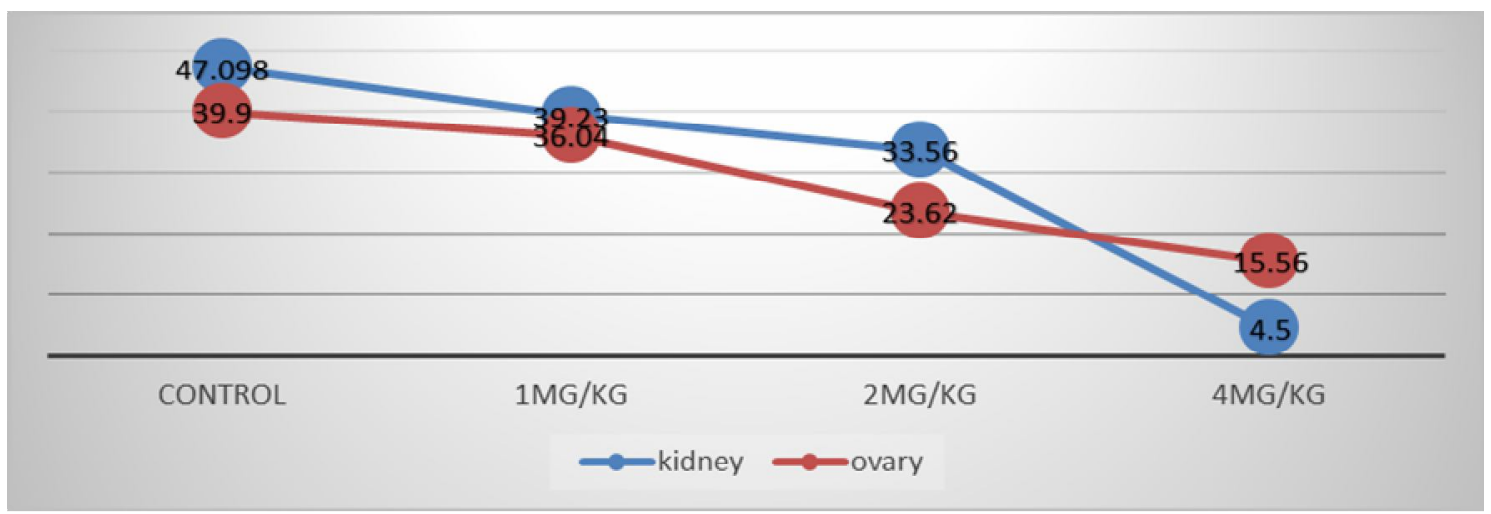

Fig. (5): Effects of silver nanoparticles on renal and ovarian glutathione peroxidase (U/gt) level in the studied groups.

\section{Histopathological results of the ovaries:}

Microscopic examination of H\&E stained ovarian sections illustrates absence of primordial follicles with abundance of stromal cells. Degeneration of primary follicles is seen with dilated congested blood vessels under the 
germinal epithelium. A lot of fibrous tissue is present in the cortex. The antral follicle contains many degenerated and necrotic cells in the cavity with presence of degeneration in oocyte and the corona radiate. All these changes occurred in a dose dependent manner as evaluated in figures (6-9).

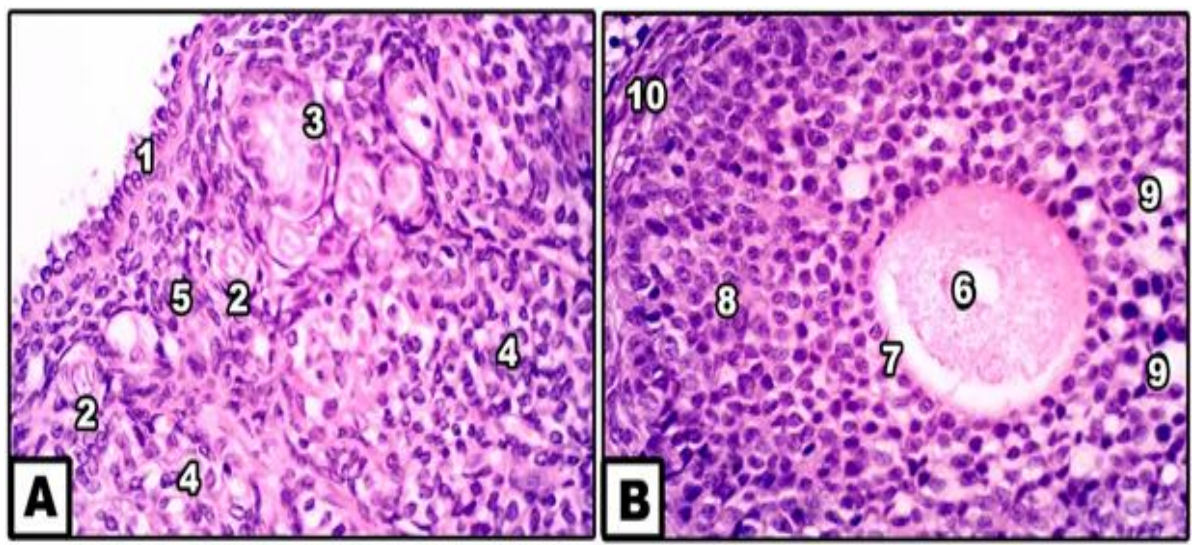

Fig. (6): A section in the ovary of the control group treated with $0.5 \mathrm{ml}$ deionized water daily by intraperitoneal (I.P) route for 28 days contains (A): the germinal epithelium (1), primordial follicles (2) Primary unilaminar follicle (3), and growing follicles (4). Note the scanty ovarian stroma (5). (B): a growing follicle contains a primary oocyte (6), corona radiata (7) and the zona granulosa (8) which illustrates vesicular spaces (9). Concentric layers of the theca folliculi (10) surround the growing follicle.

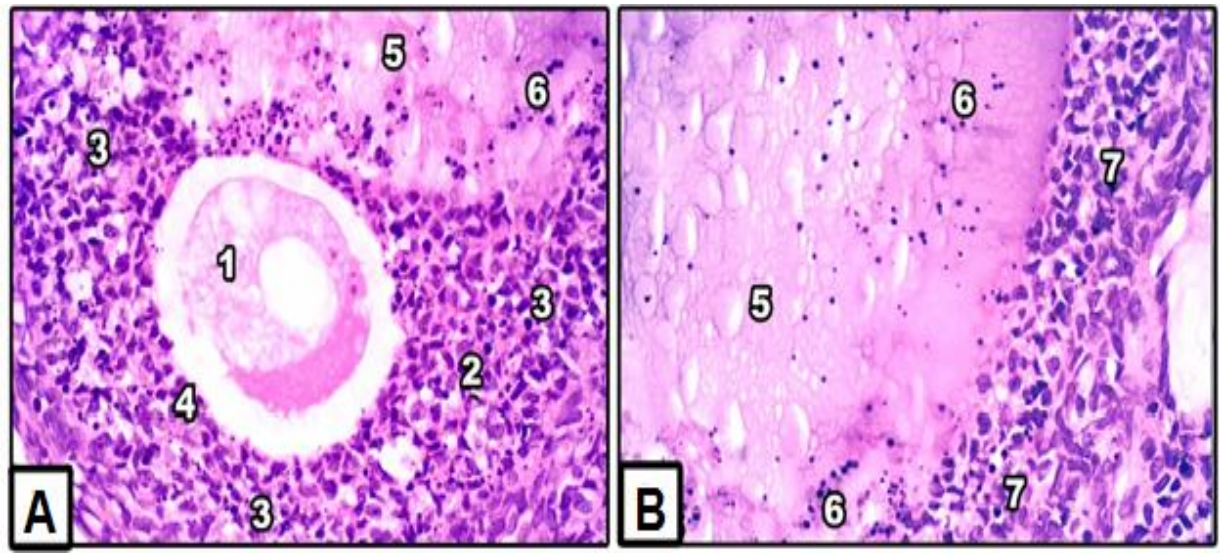

Fig. (7): A section in the ovary of group I treated with silver nanoparticles (AgNPs) of average size $7 \pm 3 \mathrm{~nm}$ at a dose of $1 \mathrm{mg} / \mathrm{kg}$ bw (1/268 of LD50) contains (A\&B): a large antral follicle illustrates a distorted primary oocyte (1), a cumulus oophorus (2) which has many cells with pycknotic nuclei (3) and a degenerated corona radiata (4). The antral cavity (5) illustrated many desquamated necrotic cells (6) and many granulosa cells with pycknotic nuclei (7). 

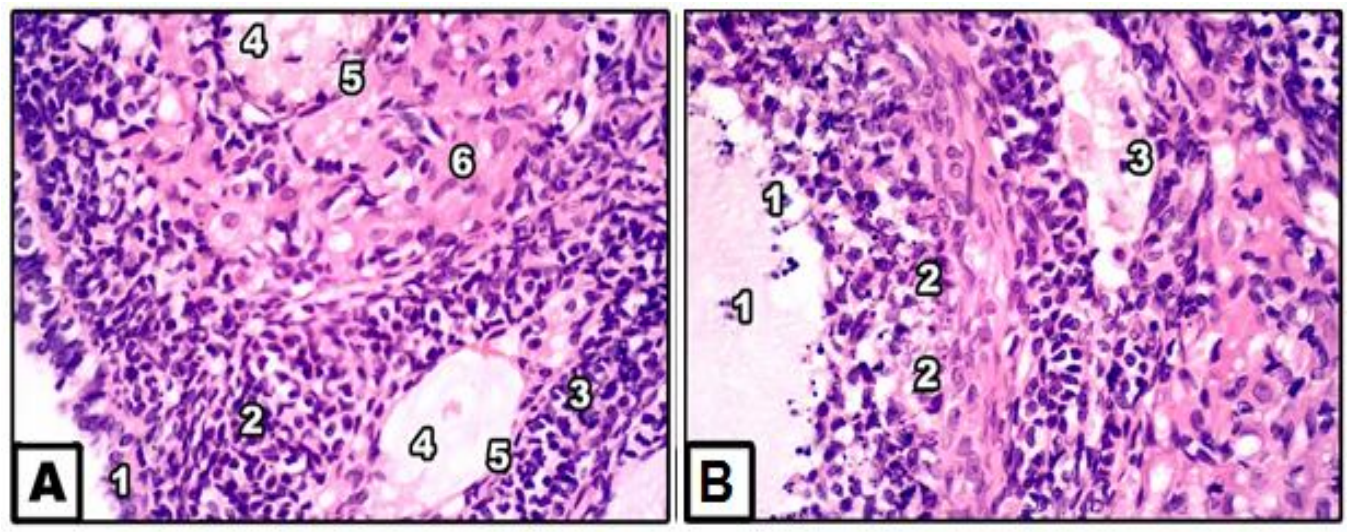

Fig. (8): A section in the ovary of group II treated with silver nanoparticles (AgNPs) of average size $7 \pm 3 \mathrm{~nm}$ at a dose of $2 \mathrm{mg} / \mathrm{kg}$ bw (1/268 of LD50) contains: (A) the germinal epithelium (1). Primordial follicles are absent with abundance of stromal cells (2). Two growing follicles (3\&4); both of them contains degenerated primary oocyte (4) with degenerated corona radiata (5). The upper one illustrates degenerated granulosa cells (6). (B) a large antral follicle contains many desquamated necrotic cells (1) in the antral cavity, many cells with pycknotic nuclei (2) in the granulosa cells. Note the dilated congested blood vessels (3)

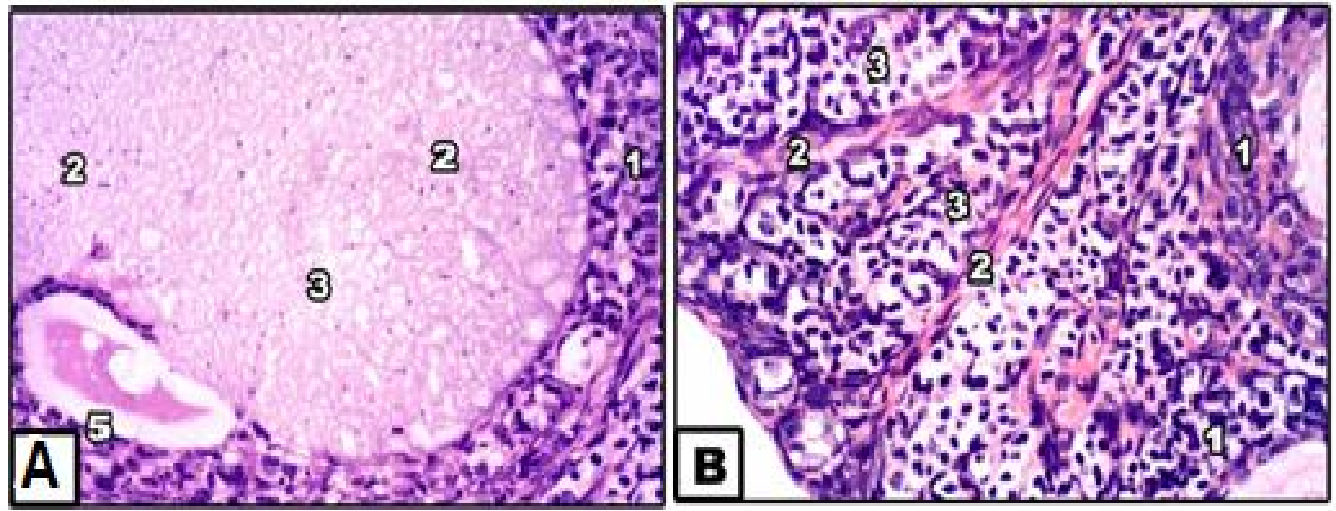

Fig. (9): A section in the ovary of group III treated with silver nanoparticles (AgNPs) of average size $7 \pm 3 \mathrm{~nm}$ at a dose of $4 \mathrm{mg} / \mathrm{kg}$ bw (1/268 of LD50) contains: (A) Two antral follicles (1) contains many degenerated cells (2) and many necrotic cells in the cavity (3). The oocyte and the corona radiata are degenerated (5). (B) A growing follicle with degenerated cells (1). A lot of fibrous tissue is present in the cortex (2) with abundance of stromal cells (3).

\section{E. Histopathological results of the kidneys:}

Microscopic examination of $H \& E$ stained renal sections illustrates that renal cortex contains renal corpuscles with obliterated Bowman's capsule and shrinkage with degenerated glomerulus. The interstitium contained many congested dilated blood capillaries. The tubules show vacuolated cytoplasm, pycknotic nuclei and karyorhyksess. All these changes occurred in a dose dependent manner as shown in figures (10-11). 

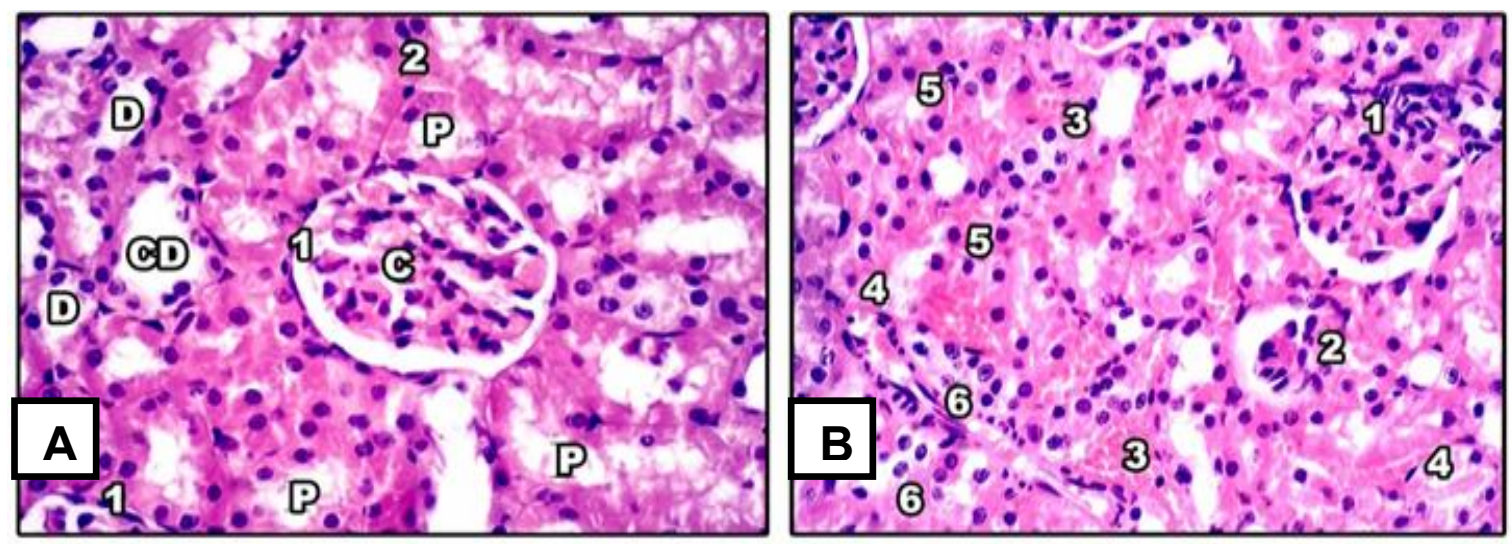

Fig. (10): Sections in the renal cortex of the control group (A. left side) treated with $0.5 \mathrm{ml}$ deionized water daily by intraperitoneal (I.P) route for 28 days and group I (B. Right side) treated with silver nanoparticles (AgNPs) of average size $7 \pm 3 \mathrm{~nm}$ at a dose of $1 \mathrm{mg} / \mathrm{kg}$ bw(1/268 of LD50). A illustrates a renal glomerular corpuscle (C) surrounded by Bowman's capsule (1), proximal convoluted tubules (P) with narrow lumen, and acidophilic cytoplasm, distal convoluted tubules (D) having a wider lumen, acidophilic cytoplasm and also collecting tubules (CD) separated by a scarce amount of interstitium containing blood capillaries (2). B illustrates a section in the renal cortex of group I contain renal corpuscles with obliterated Bowman's capsule (1) and shrinkage degenerated glomerulus (2). The interstitium contains many congested and dilated blood capillaries (3). The tubules illustrate vacuolated cytoplasm (4), pycknotic nuclei (5) and karyorhyksess (6).
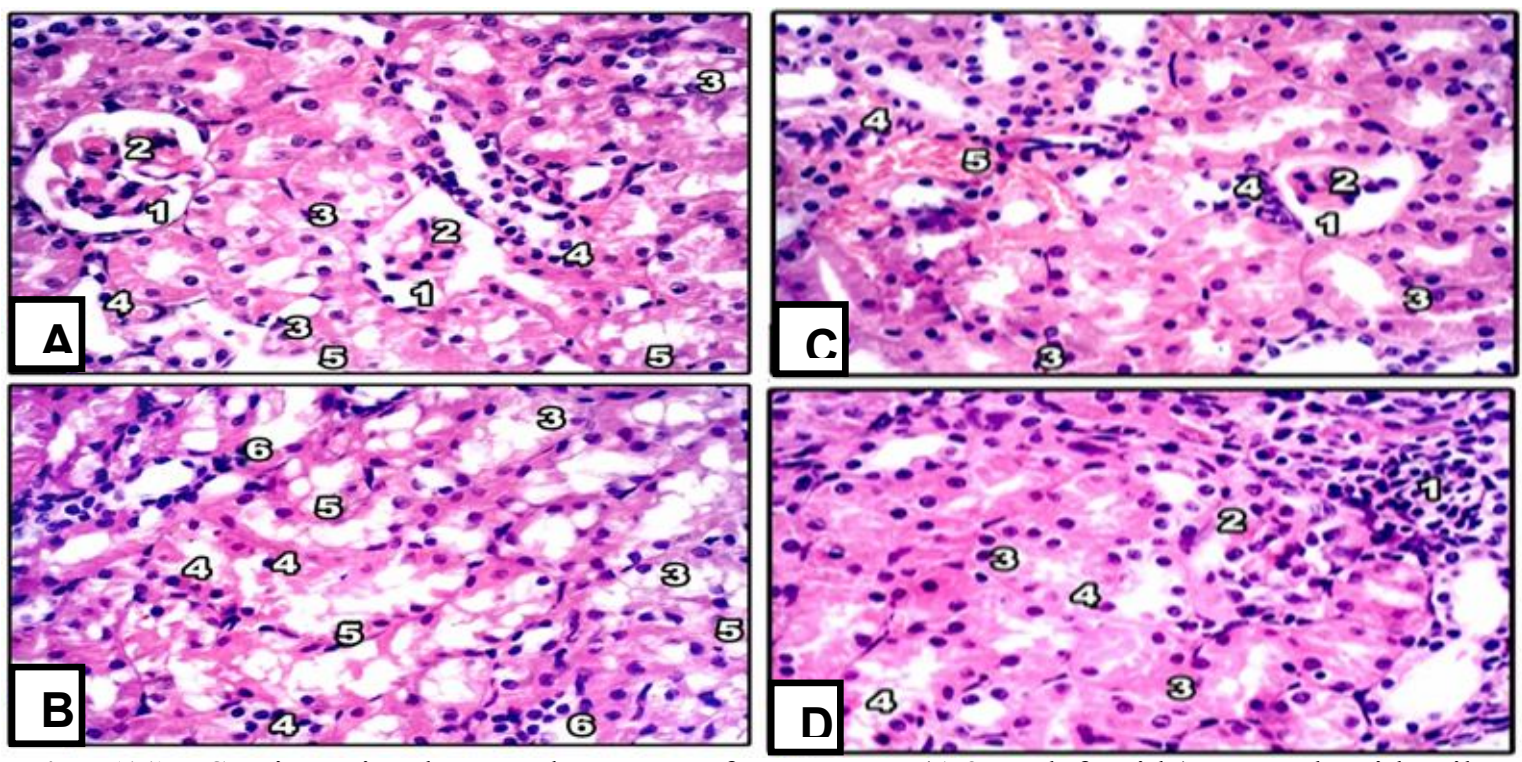

Fig. (11): Sections in the renal cortex of group II (A\&B. left side) treated with silver nanoparticles (AgNPs) of average size $7 \pm 3 \mathrm{~nm}$ at a dose of $2 \mathrm{mg} / \mathrm{kg}$ bw(1/268 of LD50) and group III (C\&D. Right side) treated with AgNPs of average size $7 \pm 3 \mathrm{~nm}$ at a dose of 4 $\mathrm{mg} / \mathrm{kg}$ bw (1/268 of LD50). A\&B illustrate sections in the renal cortex of group II contain renal corpuscles with widened Bowman's capsule (1) and shrinkage degenerated glomerulus (2). The tubules illustrate vacuolated cytoplasm (3), pycknotic nuclei (4) and karyorrhexis (5). Note the inflammatory cells in between the tubules (6). C\&D illustrate sections in the renal cortex of group III contain (C) renal corpuscles with widened Bowman's capsule (1) and shrinkage degenerated glomerulus (2). Many fibroblasts (3), inflammatory cells (4) and congested dilated blood vessels (5) appear between the tubules. (D) many inflammatory cells (1) surrounding a degenerated glomerulus with obliterated Bowman's capsule (2). The tubules are degenerated (3) and contain casts in the lumen (4). 


\section{Discussion:}

It is clear that silver NPs containing products are increasing yearly more than any other types of nanoparticles (Vance et al., 2015). The current study aimed to assess the effect of different doses of silver NPs as regard the hormonal, biochemical and histopathological changes in ovaries and kidneys of adult female Albino rats and whether or not these changes are mediated by oxidative stress.

The present study has demonstrated a significant reduction in both $\mathrm{LH}$ and FSH levels in a dose dependent manner in comparison to the control group. This disturbance of the female sex hormones (FSH and $\mathrm{LH}$ ) induced by AgNPs may referred to their possible effect on mitochondria of the functional cells that diminish their secretary function. Additionally, silver NPs are wellknown to induce oxidative stress and increase the generation of reactive oxygen species (ROS) inside tissues with subsequent cellular necrosis and apoptosis that consequently decrease the secretory function of the functioning tissues (Carlson et al., 2008). The current work agreed with in that, there was such significant reduction in LH level after exposure to silver NPs as shown in other previous studies of Rezaei-Zarchi et al. (2013) and Luaibi and Qassim (2017) whilst, reduction in FSH level was non-significantly detected.

The difference in the AgNPs influence on FSH level might be the effect of using different sizes of silver NPs. The effects of NPs are inversely proportional to their size. Small-sized NPs less than $10 \mathrm{~nm}$ behave similar to gas in which they enter human body easily via different routes with resultant tissue accumulation and disturbance of normal cellular biochemical environment (Pourmand and Abdollahi, 2012; Mostafalou et al., 2013). The average size of silver NPs used in the current study was $7 \pm 3 \mathrm{~nm}$ while Luaibi and
Qassim,2017 used different size of silver NPs about $25 \pm 5 \mathrm{~nm}$ with no available data about size for silver NPs in Rezaei-Zarchi et al. (2013) study. This change in the particle sizes can explain why there was significant reduction in FSH level in the current work in contrast to Luaibi and Qassim (2017).

As regard renal function biomarkers, the current study revealed a significant increase in serum $\mathrm{Cr}$ and BUN in all silver NPs-treated rats in a dose dependent manner compared to the control group. Similarly, Sarhan and Hussein (2014) found increase in both serum creatinine and BUN levels. Furthermore, Wen et al. (2017) reported that there was marked increase in both serum creatinine and BUN after subacute toxicity of silver NPs.

However, Sulaiman et al. (2015), reported that there was significant reduction in serum $\mathrm{Cr}$ and BUN levels after oral ingestion of silver NPs for 30 days in doses of $(10,50$, and 100 $\mathrm{mg} / \mathrm{kg}$ ). The increase in $\mathrm{Cr}$ and BUN could be elucidated through possible inflammatory effects of sliver NPs as well as generation of reactive oxygen species as represented by elevated MDA level and reduction of SOD and GPx levels in the studied groups in relation to the control group (Yarmohammadi et al., 2014).

The current study found that, there was generation of ROS in ovarian and renal tissues, since there was significant increase in MDA level and significant decrease in SOD and GPx levels by comparison with the control group in a dose dependent manner. Ovarian histopathological result of this study showed that, silver NPs pathologically impact the ovarian tissue by induction of degeneration in the primary oocytes and cells with presence of many desquamated necrotic cells and dilated congested blood vessels. Additionally, there were pycknotic nuclei in the granulosa cells with wide ovarian stroma. 
Silver NPs induced histopathological alterations occurred in a dose dependent manner. This ovarian histopathological alteration can be explained by that, ROS are involved in modulation of ovarian physiological functions, including oocytes maturation, function of corpus luteal, ovarian steroidogenesis and leukocytes infiltration. Therefore, generation of ROS inside ovarian tissue could affect ovarian functions.

Ovarian histopathological results were in agreement with Ghorbanzadeh et al. (2012). They reported that, silver NPs decreased number of primary and secondary follicles after intravenous injection (Ghorbanzadeh et al., 2012; Han et al., 2016).

The reduction in primary oocytes can explain that silver NPs affected ovulation and caused its inhibition. Probably, that is why nanoparticle after entering the blood, could move into body organs, such as ovaries, penetrate inside cells causing oxidative stress that leads to activation of oxidative stress factors in ovarian cells leading to apoptosis (Johnson, 2003). Considering increased degeneration in primary oocyte associated with decreased antioxidant status, we can come close to this fact that silver NPs at different doses exert their harmful impact partially by inducing oxidative stress. To understand how silver NPs result in oxidative stress, we should note the role of SOD in neutralizing the ROS production as well as its importance in protecting the growing follicles against ROS (Bilbao et al., 2015).

Regarding histopathological examination of the kidney, the current study revealed that all changes occurred in a dose dependent manner. Exposure to silver NPs could cause renal injury via a reduction in ion pump transport in the lining of the renal tubules with subsequent renal tubule degeneration. The resulting inflammatory cell infiltration in renal tissues following exposure to silver NPs suggests that these fine particles may interact with the interstitial tissues of the kidney.

This indicates that silver NPs may also induce oxidative stress in renal tissues leading to generation of ROS and causing an immune response as well as immune-mediated inflammatory injury. These results are consistent with increased MDA levels and decreased of SOD and GPx levels in renal tissue (Almansour et al., 2016).

The present work supported with Sarhan and Hussein. (2014) as they assessed the acute effects of silver NPs. They evaluated that after rats were injected intraperitoneally at a dose of $2,000 \mathrm{mg} / \mathrm{kg}$ body weight followed by a second injection after 48 hours, the renal cortex in kidney tissue from the treated group revealed swollen epithelium and vacuolated cytoplasm, with some nuclei showing hypertrophied nucleoli. Swelling of the tubular epithelium, cytoplasmic vacuolization, increased glomerular cellularity, obliteration of Bowman's space and finally inflammatory cells were seen in between the tubules. Furthermore, Sardari et al. (2012) investigated the histopathology of kidney after oral ingestion of silver NPs at size $70 \mathrm{~nm}$ for 30 days on adult male Wister rats. They found tubular damage and increased glomerular pressure which causes glomerular atrophy.

In conclusion, the alteration of antioxidant status with generation of ROS in both renal and ovarian tissues can be explained by elevation of MDA levels with reduction of both SOD and GPx level in renal and ovarian tissues. Minding crosslink between the silver NPs-induced follicular degeneration in ovary and shrinkage with degeneration in kidney glomeruli together with alteration in antioxidant status in renal and ovarian tissues, our present study comes to the fact that, silver nanoparticles induce their harmful effects partially through generation of ROS in tissues. 
Great numbers of studies have reported the possible effects of silver NPs on reproduction and development and renal system; however, data are still limited and the studies were achieved by using a wide range of doses $(15 \mu \mathrm{g} / \mathrm{kg}-1000 \mathrm{mg} / \mathrm{kg})$ and sizes $(6.45-32 \mathrm{~nm})$ of silver NPs. To measure the whole toxic effects of doses and sizes of silver NPs on reproductive and renal toxicity, further studies are needed to fill the gap and to confirm the reproducibility of study results.

\section{References}

Abdel-Halim, E.S.; El-Rafie, M.H. and AlDeyab, S.S. (2011): "Polyacrylamide/guar gum graft copolymer for preparation of silver nanoparticles". Carbohydrate Polymers, 85(3): 692-697.

Almansour, M.; Jarrar, Q.; Battah, A.; et al. (2016): "Renal histopathological alterations induced by nanosilver toxicity: the size effect". Micro \& Nano Letters, 11(12): 862-865.

Bancroft, J.D. and Gamble, M. (2008): "Theory and practice of histology techniques". In: Health Science $\left(6^{\text {th }}\right.$ Edition), Churchill Livingstone, Elsevier, China, P.P. 83-134.

Batista, C.A.S.; Larson, R.G. and Kotov, N.A. (2015): "Non additivity of nanoparticle interactions". Science, 350(6257): 1242477.

Bilbao, M.G.; Di Yorio, M.P.; Galarza, R.A.; et al. (2015): "Regulation of the ovarian oxidative status by leptin during the ovulatory process in rats". Reproduction, 149(4): 357-366.

Carlson, C.; Hussain, S.M.; Schrand, A.M.; et al. (2008): "Unique cellular interaction of silver nanoparticles: sizedependent generation of reactive oxygen species". The Journal of Physical Chemistry B, 112(43): 13608-13619.

de Jong, E.; Kauffold, J.; Engl, S.; et al. (2013): "Effect of a GnRH analogue (Maprelin) on the reproductive performance of gilts and sows". Theriogenology, 80(8): 870-877.

Dykstra, M.J. and Reuss, L.E. (2011): "Biological electron microscopy: theory, techniques, and troubleshooting". In: Science and Business Media, (2 ${ }^{\text {nd }}$ Edition), North Carolina, United States, P.P. 74-123.

El Mahdy, M.M.; Eldin, T.A.S.; Aly, H.S.; et al. (2015): "Evaluation of hepatotoxic and genotoxic potential of silver nanoparticles in albino rats". Experimental and Toxicologic Pathology, 67(1): 21-29.

Ghorbanzadeh, V.; Moshtaghian, S.J.; Habibian, S.; et al. (2012): "Influence of nanosilver on secondary follicles of ovary via intraperitoneal injection in rats". European Journal of Experimental Biology, 2(4): 1367-1369.

Han, J.W.; Jeong, J.K.; Gurunathan, S.; et al. (2016): "Male-and female-derived somatic and germ cell-specific toxicity of silver nanoparticles in mouse". Nanotoxicology, 10(3): 361-373.

Johnson, A.L. (2003): "Intracellular mechanisms regulating cell survival in ovarian follicles". Animal Reproduction Science, 78(3-4): 185-201.

Luaibi, N.M. and Qassim, H.A., (2017): "Dose and time dependent effects of silver nanoparticles (AgNPs) on ovarian histology and serum levels of sex hormones in female rats". Pakistan Journal of Biotechnology, 14(4): 663672.

Mostafalou, S.; Mohammadi, H.; Ramazani, A. et al. (2013): "Different biokinetics of nanomedicines linking to their toxicity: 
an overview". Daru Journal

Pharmaceutical Sciences, 21(1):14.

Patterson, A.L. (1939): "The Scherrer formula for X-ray particle size determination". Physical Review, 56(10): 978.

Park, E.J.; Bae, E.; Yi, J.; et al. (2010): "Repeated-dose toxicity and inflammatory responses in mice by oral administration of silver nanoparticles". Environmental Toxicology and Pharmacology, 30(2): 162-168.

Pourmand, A. and Abdollahi, M. (2012): "Current opinion on nanotoxicology". Daru Journal Pharmaceutical Sciences, 20(1): 95.

Rezaei-Zarchi, S.; Taghavi-Foumani, H. and Negahdary, M. (2013): "Effect of Silver Nanoparticles on the LH, FSH and Testosterone Hormones in Male Rat". Journal of Babol University of Medical Sciences, 15(1): 25-29.

Sardari, R. R. R.; Zarchi, S. R.; Talebi, A.; et al. (2012): "Toxicological effects of silver nanoparticles in rats". African Journal of Microbiology Research, 6(27): 5587-5593.

Sarhan, O.M.M. and Hussein, R.M. (2014): "Effects of intraperitoneally injected silver nanoparticles on histological structures and blood parameters in the albino rat". International Journal of Nanomedicine, 9: 1505-1517.

Schäfer, B.; Vom Brocke, J.; Epp, A.; et al. (2013): "State of the art in human risk assessment of silver compounds in consumer products: a conference report on silver and nanosilver held at the BfR in 2012". Archives of Toxicology, 87(12): 2249-2262.

Slavin, Y.N.; Asnis, J.; Häfeli, U. O. et al. (2017): "Metal nanoparticles: understanding the mechanisms behind antibacterial activity". Journal of Nanobiotechnology, 15(1): 65.

Sulaiman, F.A.; Adeyemi, O.S.; Akanji, M.A.; et al. (2015): "Biochemical and morphological alterations caused by silver nanoparticles in Wistar rats". Journal of Acute Medicine, 5(4): 96-102.

Tiwari, R., Singh, R. D., Khan, H., et al. (2017): "Oral subchronic exposure to silver nanoparticles causes renal damage through apoptotic impairment and necrotic cell death". Nanotoxicology, 11(5): 671-686.

Van Dong, P.; Ha, C.H. and Kasbohm, J. (2012): "Chemical synthesis and antibacterial activity of novel-shaped silver nanoparticles". International Nano Letters, 2(1): 9.

Vance, M.E.; Kuiken, T.; Vejerano, E.P.; et al. (2015): "Nanotechnology in the real world: Redeveloping the nanomaterial consumer products inventory". Beilstein Journal of Nanotechnology, 6(1): 17691780.

Wen, H.; Dan, M.; Yang, Y.; et al. (2017): "Acute toxicity and genotoxicity of silver nanoparticle in rats". Plos One, 12(9): e0185554.

Yarmohammadi, P.; Arabi, M. and Yarmohammadi, P. (2014): "Subacute dermal toxicity investigation of nanosilver on serum chemical biomarkers in male mice". Nanomedicine Journal, 1(4): 285-291. 


\title{
سمية نانو الفضة على كلى و مبايض إناث الجرذان البيضاء
}

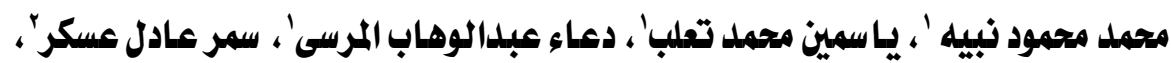

أحمد محمد البدويهي"، منى أحمد الحاروني'

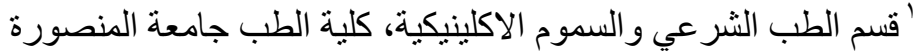

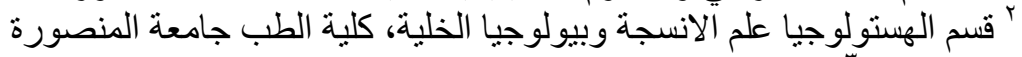 \\ "مركز النانوتكنولوجي، كلية الطب جامعة المنصورة
}

إن جسيمات نانو الفضة هي واحدة من مواد النـانو الأكثر حيويـة وجاذبيـة بين العديد من جسيمات النانو

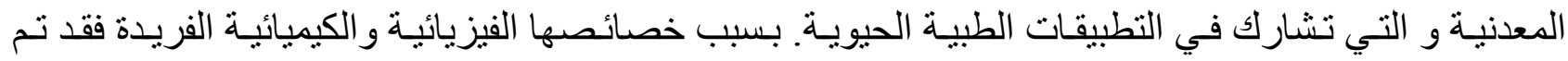
استخدامها في العديد من التطبيقات ، بما في ذلك مضادات البكتيريا ، و الصناعة و أغر اض المنزل و المنتجات الصحية والاستهلاكية و طلاء الأجهزة الطبية و أجهزة الاستشعار البصرية و مستحضرات التجميل. ويزداد

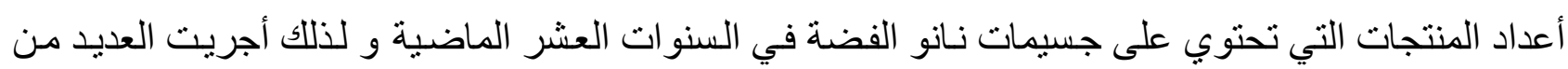

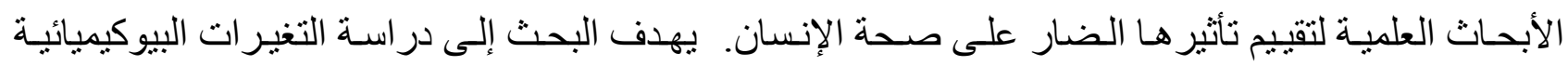

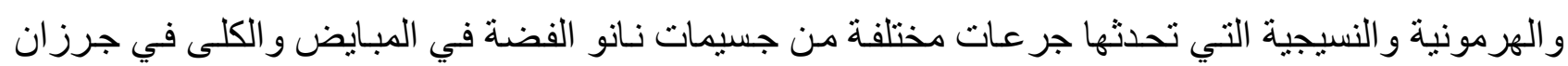

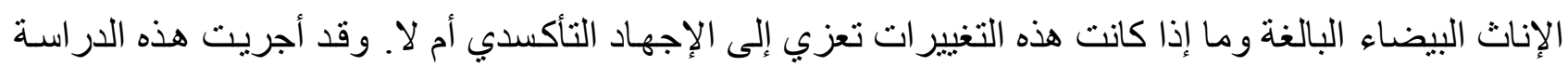

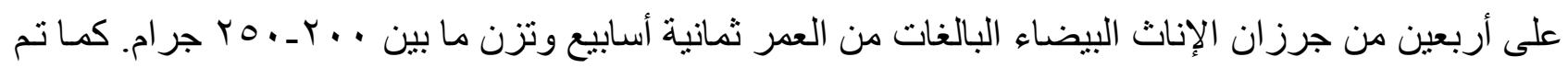

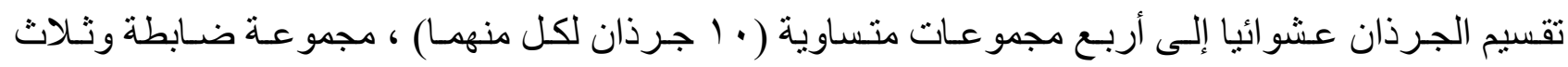

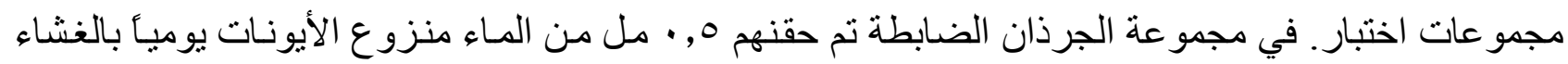

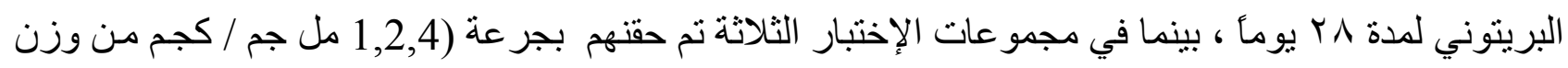

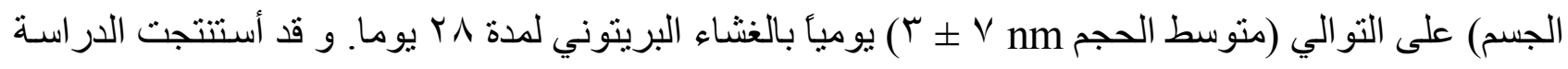

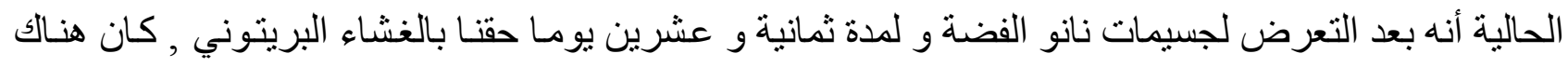
تدهور في وظائف الكلى ووظائف الجهاز التتاسلي للإناث ، فضلا عن تغير في أنسجة الكلى و المبايض اعتمـادا

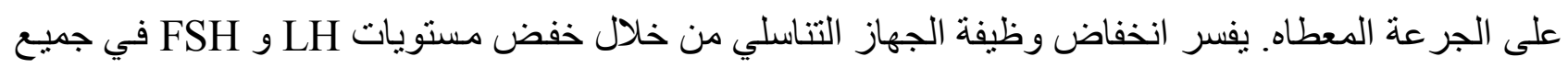

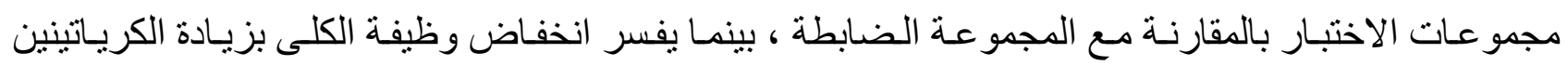

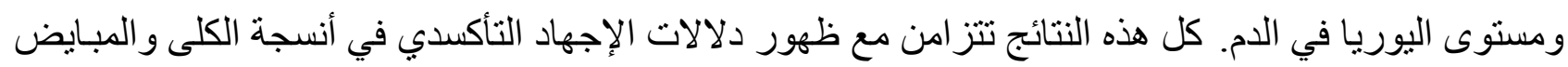

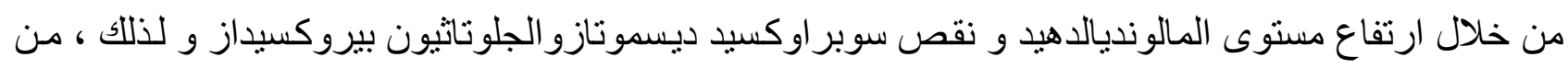
الممكن رجوع تللك التأثير ات الصحية السامة لجزئيات نانو الفضة إلى إجهادهـا التأكسدي. وحتى الآن ، لا توجد

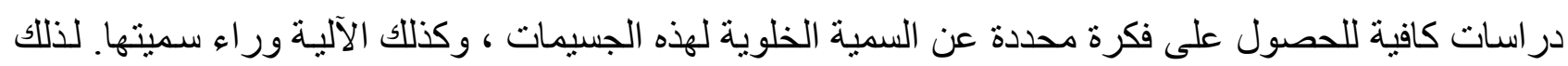

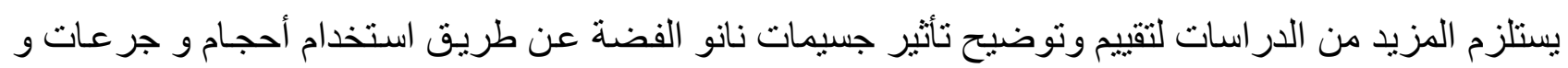
طرق للتعرض مختلفة. 